\title{
15-M. LA REAPARICIÓN DE LAS LUCIÉRNAGAS [1]
}

\author{
Alfredo Apilánez \\ Centro de Estudios ACCES, Barcelona
}

\begin{abstract}
Resumen: La extraordinaria sorpresa provocada por el surgimiento del llamado movimiento 15M tiende a dejar en segundo plano el agudo deterioro de las condiciones de vida de la población española que lo ha generado. Asimismo, la enorme decepción que el movimiento refleja hacia la llamada clase política es una consecuencia del peculiar desarrollo histórico español de las últimas décadas y de la frustración acumulada por las esperanzas defraudadas por la transición de los años setenta. Se trataría pues de explorar cuáles son las raíces históricas del levantamiento quincemayista y las condiciones concretas en las que ha tenido lugar su eclosión.
\end{abstract}

Palabras clave: fascismo postmoderno, neoliberalismo, levantamiento

\section{5-M. The reappearance of the Fireflies}

Abstract: The extraordinary surprise caused by the emergence of so-called 15$\mathrm{M}$ movement tends to overshadow the grave deterioration of living conditions of the Spanish population that has generated it. Also, the huge disappointment that the move reflects the call to politicians is a consequence of the peculiar Spanish historical development of recent decades and the pent-up frustration hopes dashed by the transition from the seventies. It would thus be to explore what are the historical roots of the uprising quincemayista and the concrete conditions in which there has been hatching.

.Keywords: postmodern fascism, neoliberalism, neolifting

Y en el peligro de extinción de las últimas luciérnagas resurge el magma incandescente que aliviará su agonía, hasta donde y cuando dure la fe en el efecto contagioso de la minúscula luz, del instantáneo destello que parpadea e insiste, por permanecer, por multiplicarse desde la nada que es el primer paso, el primer ¡basta!, el postrer repliegue por admitir lo inadmisible, mientras la noche aún no clarea y entre las sombras tintinean las breves luces de las luciérnagas que no se rinden. Tonio Santiuste [2]

Intentarlo otra vez. Fracasar de nuevo. Fracasar mejor.. Samuel Beckett 


\section{Un bosquejo histórico}

En el páramo de la descarnada y yerma realidad política española brilla de nuevo, todavía titilante y frágil, la luz de las luciérnagas.

Cuando todos los politicastros, plumillas, tertulianos y demás corifeos de Su Majestad Neoliberal certificaban gozosamente la extinción del último rescoldo de la, otrora rutilante, tradición emancipadora de la izquierda.

Cuando el triunfo de un posibilismo político de vía única, sin distinción de credos o tradiciones ideológicas y postrado servilmente ante los designios de la implacable internacional del capital, hacía indistinguibles los poderes electos y fácticos en la plutocracia dominante.

Cuando el único peligro para el orden formalmente democrático parecía provenir de los zarpazos fascistizantes de grupos de extrema derecha que azuzaran, con sus broncos y demagógicos bramidos, la anomia y la degeneración moral de la llamada mayoría silenciosa.

Cuando el nadir del instinto de rebelión de la juventud, aparentemente despolitizada e individualista, coincidía con la catástrofe del paro masivo y el bloqueo de las posibilidades de construcción vital para toda una generación, sobradamente preparada.

Cuando las trituradoras ideológicas de la publicidad, la televisión basura, el fútbol y demás apisonadoras de embrutecimiento colectivo producían legiones de onanistas sentimentales en un ambiente de narcosis generalizada: un magma dócil al poder de tullidos sociales, cuya relación enajenada con el mundo circundante se reduce a tomarlo como simple instrumento para su placer y la satisfacción de sus intereses individuales, volviendo de paso cínicamente la espalda a su verdadera faz, miserable e injusta, para evitar contaminarse con su iniquidad.

Cuando todo ello ocurría en la sima del mayor desastre económico de la historia reciente, causante directo del agudo agravamiento de las condiciones básicas de existencia de la mayor parte de la población.

Cuando, en fin, el atropello implacable de la dignidad y de los escasos colchones de pseudobienestar de la ciudadanía parecía campar por sus respetos y la clase dominante creía haber logrado su distópico objetivo último de convertir al ser humano en un mero engranaje de la maquinaria productivista... 
Repentinamente, en este erial de postración y desesperanza, surge el resplandor quincemayista, que irrumpe como un relámpago de ilusión colectiva en la negrura desencantada de la delicuescente realidad del fascismo postmoderno a la española.

Como luciérnagas que se resisten a extinguirse, a sucumbir a todos los pesticidas ideológicos y deforestaciones morales que esquilman irremisiblemente su hábitat, aparecen súbitamente, todavía embrionarias y desvalidas, esas plazas insurgentes donde se esboza tentativamente la constitución de un auténtico poder popular.

Estas minúsculas pero irredentas luces, cuyo destello pugna por multiplicarse, insisten en resistirse a la consumación de los postreros repliegues de la dignidad popular ante los furibundos embates de los adalides de la ofensiva neoliberal, para que su parpadeo contagioso pueda reavivar la llama de la resistencia contra la deshumanización rampante.

Múltiples encrucijadas y arduas tareas se agolpan ante este intento de ruptura del panorama desolador de derrota y sumisión de las clases populares a los continuos zarpazos y agresiones, que la voracidad creciente del modo de producción vigente exige como sacrificios al ídolo insaciable a cuya adoración entrega la ofrenda de la dignidad humana: el numen pagano de la acumulación de capital.

La sorpresa y novedad del levantamiento conllevan la necesidad de repensar radicalmente las formas de lucha política tradicionales, inadaptadas a las nuevas realidades de la sociedad actual, tratando asimismo de explicar las condiciones en que su irrupción ha tenido lugar.

¿Cómo es posible que, precisamente en uno de los países aparentemente más sumisos y domesticados de Occidente, prendiera la chispa de la rebelión contra la farsa pseudodemocrática, sirviendo además de faro e inspiración a levantamientos semejantes en el mundo entero?

¿Cuáles podrían ser los asideros que ayudaran a extender y asentar las incipientes resistencias a la condena dictada por el bloque hegemónico neoliberal al empobrecimiento vitalicio de todo un pueblo?

¿Cómo preservar el activismo y la lucha sin dejarse fagocitar por los agentes de la desmovilización ciudadana en los tabloides y en la pantomima parlamentaria, prestos a aherrojar cualquier disidencia que pueda agrietar su férreo monopolio ideológico?

¿Qué tipo de acciones asumir como prioridades para que estas titilantes luces de rebeldía puedan iluminar los oscuros rincones de la realidad inclemente en la que vivimos, pugnando por crear otro tipo de relaciones humanas opuesto a la atomización mutiladora de la vida que impone el régimen de propiedad privada?

Ensayar respuestas a estas cuestiones exige ampliar el foco de análisis, abarcando la realidad histórica española de los últimos decenios de falso bienestar y paños calientes en la gestión capitalista del país, tratando así de iluminar las causas del enorme batacazo del desplome económico en curso y las extremas condiciones de frustración colectiva en las que ha germinado el levantamiento. 
¿Qué ha ocurrido para que los triunfales eslóganes del "España va bien" y la, apoteósicamente proclamada, llegada a la Champions League de las potencias mundiales (de los que se ufanaban los dos últimos títeres peripatéticos al frente del gobierno), se tornaran hirientes sarcasmos al derrumbarse con estrépito la corrompida carcasa que los sustentaba?

La historia reciente de España refleja una fractura generacional que escinde en dos bloques, sociológicamente bien diferenciados, la población del país: los padres del baby boom de los años 60 y sus descendientes. La generación nacida en los 40 y 50, criada todavía en los rigores de la posguerra y el mísero aislamiento de la autarquía, gozó en su tránsito a la madurez de posibilidades materiales de emancipación personal como probablemente nunca se hayan producido en este país.

Después del trágico truncamiento del único intento histórico serio de modernización de las arcaicas estructuras de un país atrasado y mísero, simbolizado en el triste sino de la Segunda República, y del oscuro, criminal y sórdido franquismo de la posguerra, en los años 50 se produce por fin la incorporación de la economía española a las corrientes dominantes del capitalismo mundial.

El "Bienvenido Mister Marshall", el turismo de sol y playa encarnado en el topicazo carpetovetónico de las suecas en Benidorm, las lavadoras, los seiscientos y las remesas de los emigrantes receptores de las migajas del milagro económico europeo conforman, aún en dictadura (lo que menos le ha importado siempre al poder económico es la superestructura política con tal de que fuera servil a sus designios), una idiosincrasia de pedestre y cutre modernidad. Quedaban así atrás los rasgos más míseros de la España negra, rural, de machadiano cerrado y sacristía, vislumbrándose en apariencia una vía hacia la reiteradamente abortada modernización del país.

Los sectores industriales tradicionales, los nuevos nichos de inversión creados por el desembarco de las multinacionales europeas y estadounidenses y la ya mencionada tabla de salvación que supuso convertir España en lugar de solaz para los laboriosos centroeuropeos suministran, en este contexto expansivo, la demanda de trabajo que absorbe el grueso de la mano de obra existente. Se conforma, de esta suerte, una realidad de estabilidad laboral y seguridad económica para una parte importante de la población.

Por fin cuaja el sueño de los tecnócratas opusdeístas del desarrollismo: una pujante clase media que mantenga la vitalidad económica y amortigüe los agudos conflictos de clase que habían desangrado el país.

El final de la dictadura y los subsiguientes juegos florales de la sacrosanta transición a la anhelada democracia completan esta visión pseudoprogresista y vitalmente optimista de toda una generación. Una hornada afortunada que batió los récords históricos de natalidad, accedió por un módico precio a la vivienda en propiedad y al pisito en la playa, votó llena de vanas ilusiones en las primeras elecciones democráticas, llenó las plantillas funcionariales de las nuevas administraciones autonómicas y municipales y disfrutó, en fin, de la fugaz ilusión del progreso patrio. Unos padres orgullosos de mandar a sus abundantes hijos masivamente a la universidad, que presenciaban gozosos el final del crónico aislamiento español y la ansiada, aunque totalmente ficticia, incorporación por fin de la piel de toro a los estándares europeos de bienestar. 
Este trampantojo de bonanza y confort desactivó la resistencia popular y la capacidad de confrontación política del grueso de una población deslumbrada por la mejora drástica, y aparentemente sólida, de sus condiciones de vida. Acomodamiento harto comprensible pensando en la abismal diferencia entre la miseria, el estraperlo y la carcunda sufridos por la generación de la guerra y la posguerra, y la relativa, en comparación, opulencia del tardofranquismo (reflejada especularmente en la naïf publicidad televisiva), que parecía acercar al españolito de a pie a las comodidades del manoseado cliché hollywoodiense del american way of life.

El gran triunfo sociológico del capitalismo de posguerra de los llamados "treinta gloriosos", al desactivar la oposición beligerante de las clases trabajadoras incorporándolas a unos niveles relativamente holgados de consumo que parecían confirmar el mito reformista de la creciente participación de las clases populares en las migajas del desarrollo capitalista, llegó así tardíamente a España y pareció por un momento columbrar un horizonte venturoso y desahogado.

Esta simbiosis antropológica entre el consumismo adherido al espejismo tecnológico (falso legitimador del progreso social) y la supuesta calidad de vida "a la española", tan alejada de los puritanos y metódicos centroeuropeos, arraigó profundamente en el inconsciente colectivo del grueso de la nueva clase media, integrándola hasta la médula en la legitimación del binomio democracia formal/economía de mercado.

La lucha política y la beligerancia de los trabajadores quedaban arrumbadas en el desván de los trastos viejos de tiempos ya periclitados ante la consolidación del hombre unidimensional, brillantemente descrito por Marcuse: un individuo alienado y embarcado con fruición en la estéril búsqueda de la felicidad a través del confort material, totalmente anestesiado por la publicidad embriagadora, la manipulación de los deseos y la canalización inofensiva de la disidencia, sin tentación alguna de crítica social o de oposición al totalitarismo algodonoso de la omnímoda sociedad de consumo.

Esta es la clave de bóveda de las tan traídas y llevadas degeneración ideológica y vertiginosa decadencia política de la izquierda tradicional española, simbolizadas por las debacles electorales y la casi total desaparición de la escena del Partido Comunista, principal organización de la lucha antifranquista. Su base social, obrerista y politizada, muta radicalmente ante una puntual y excepcional confluencia de circunstancias económicas, sociológicas, políticas y demográficas que enmarcaron la edad de oro del desarrollismo español y apuntalaron el aburguesamiento de varias generaciones, que vivían mucho mejor que sus malhadados padres y abuelos y confiaban en poder transmitir ese recién conquistado estatus pequeñoburgués a sus descendientes.

Comprendiendo este sustrato histórico de conformismo y autosatisfacción de amplias capas del pueblo llano se evitarían las frecuentes lágrimas de cocodrilo vertidas por las esperanzas defraudadas por la "inmaculada" transición y el primer socialismo otánico y reconversor. O por la traición a sus ideales revolucionarios de un Partido Comunista, reformista hasta la médula e integrado dócilmente en el nuevo régimen monárquico y furibundamente proamericano. 
El mismo proceso socioeconómico de mejora temporal y excepcional de las condiciones de vida de la clase trabajadora que alumbró el revisionismo alemán, previo a la traición internacionalista de la dirigencia del SPD en el estallido de la Primera Guerra Mundial, se dio en la transición pilotada por la monarquía franquista con el PCE y el PSOE.

Esta aceptación total de las amañadas reglas del juego de la democracia formal por parte de la pseudoizquierda, integrada impúdicamente en la nueva arquitectura institucional, reflejó de forma mediata la radical transformación de su militancia en aquellos que, contraviniendo la rotunda máxima marxiana, creían tener ya mucho más que perder que sus cadenas de proletarios. Tiempo ha que quedaban abandonados definitivamente el mono azul, el marxismoleninismo, los piquetes obreros y las escaramuzas con los grises de la, por otro lado, heroica resistencia antifranquista.

Si a todo ello se añade la ávida voracidad en la asunción de cargos y prebendas por unas cúpulas dirigentes ansiosas por incorporarse a las abundantes poltronas que ofrecía el Régimen recién instaurado, abandonando de paso cualquier conexión orgánica con los movimientos sociales y vecinales, se completa la casi total desaparición de las organizaciones anticapitalistas del panorama institucional y social.

Los escasos grupúsculos radicales, aún impenitentemente revolucionarios, penaron orillados en la irrelevancia marginal y el sectarismo, anclados en el culto acrítico y anacrónico de los santones laicos de las tradiciones anarquista y comunista y consumidos en inanes luchas intestinas y fraccionarias. Descolocados por su incomprensión de los nuevos fenómenos sociológicos e incapaces de actualizar su ideario y sus tácticas decimonónicas a las nuevas realidades del fascismo postmoderno tardocapitalista, siguieron dando tumbos oscilando entre el victimismo propio de las minorías sin vocación de dejar de serlo y el irrealismo aventurero de sus rígidos y obstinadamente ortodoxos planteamientos programáticos, sin querer reconocer que la tierra se había movido ya bajo sus pies.

La deriva terrorista de algunas de estas organizaciones (GRAPO, FRAP...) prueba fehacientemente la desesperada huida hacia adelante y la pérdida de sentido de la realidad de sus desnortados dirigentes, al compás del abandono masivo de los postulados revolucionarios por parte de las bases obreras. Siendo este callejón sin salida el símbolo trágico de la insania política a la que les condujo negarse a ver la radical transformación de las "condiciones subjetivas", mientras trataban patéticamente de forzarlas a encajar mediante la violencia en esquemas ya totalmente trasnochados.

Como la historia demuestra, las revoluciones clásicas en el primer mundo terminaron cuando el capitalismo triunfante posterior a la Segunda Guerra Mundial fue capaz de constituir una clase media con unos niveles mínimos de bienestar material que desactivaron los últimos rescoldos de obrerismo revolucionario. Como vemos ahora, sólo la miseria, el riesgo de exclusión social y el agostamiento de las posibilidades de emancipación personal de amplias capas de la población pueden provocar que prenda de nuevo la mecha de la revuelta.

Y así, en una nueva vuelta de tuerca de la montaña rusa del ciclo económico capitalista, la milagrosa excepcionalidad de esta boyante coyuntura, única en la 
historia del capitalismo español y europeo, pronto daría síntomas claros de caducidad y agotamiento.

El brusco final de este fugaz espejismo de prosperidad y bonanza y el comienzo de la abrupta reacción neoliberal contra el capitalismo keynesiano de posguerra comenzaron a manifestarse agudamente con el crack del petróleo de mediados de los setenta y su intenso, aunque retardado, impacto en la endeble economía española. Y, como en un anticipo histórico de la hecatombe actual, el quebradizo armazón, que a duras penas sostenía el pomposamente denominado "milagro económico español", rápidamente comenzaría a mostrar sus corroídas costuras y a revelar la carcomida carcasa que encubría su lustrosa fachada.

El retraso en afrontar la gravedad de la nueva situación, provocado por la prioridad política de culminar la transformación institucional de la dictadura franquista en democracia partitocrática, causó un paro estratósferico y una urgente necesidad de renovación de la obsoleta estructura económica heredada del franquismo. A este diktat del gran capital se entregó, con medidas draconianas, el antiguo partido de Pablo Iglesias y Largo Caballero, aplicándose con pasión de advenedizo a la brutal implantación del neoliberalismo thatcheriano en España. Provocando así, con implacable mano de hierro, los desgarros sociales de la brutal reconversión industrial felipista, aderezados con el grotesco telón de fondo de los "marioscondes", yuppies y la beautiful people de los yates y las fiestas de los jeques mafiosos marbellíes. Este fue el trasunto hispano del incipiente capitalismo financiero del pelotazo y la ostentación, bien alejado del ascetismo discreto de los antiguos capitanes de la industria fordista, más weberianos en su ética protestante de sacrificio, disciplina y frugalidad.

Mientras tanto, el reformismo socialdemócrata, adaptado históricamente al tambaleante Wellfare State, quedaba definitivamente fuera del curso de la historia ante el vaciamiento de soberanía de ese Estado, totalmente devorado por la metástasis financiera del capital, ejemplificada en los furibundos embates neoliberales del nuevo conservadurismo anglosajón.

Fracasaba así, destruido en añicos, el utópico sueño dorado revisionista y eurocomunista de un capitalismo popular auspiciado por "Papá Estado", arrojando de paso al sumidero de la historia la quimera típicamente reformista de la creciente participación obrera en las sobras de la prosperidad al alimón con los excepcionalmente dadivosos y paternales patronos.

Rápidamente, el ariete neoliberal resucitaría la cruda lucha de clases (que van ganándola ellos, como cínica, pero certeramente, afirmara el tiburón de las finanzas Warren Buffet), dejando a los renegados socialdemócratas compuestos y sin novia. Forzándoles además, para no perder el paraguas del poder, a abrazar desvergonzadamente, con la fe del converso, el nuevo credo del estado mínimo y la sobreexplotación de los trabajadores, volviéndose de este modo totalmente indistinguibles de la derechona de toda la vida.

Si ante este infausto panorama la precaria cohesión social no saltó ya en pedazos a mediados de los ochenta fue principalmente por la mascarilla de respiración asistida que supuso para la anémica economía española la integración en el club de Bruselas y el consiguiente aluvión de fondos europeos. Plan Marshall redivivo a escala peninsular y destinado 
principalmente a convertir a España en un buen mercado para la exportación de las locomotoras centroeuropeas, culminando el desmantelamiento de su propia industria y generando un efecto riqueza necesario para mantener la demanda exterior. Este cambalache neocolonial produjo inmediatamente un déficit comercial récord, totalmente impagable en cuanto las tornas cambiaran y la disparatada inflación de activos especulativos agotara su delirante recorrido $\left[{ }^{3}\right]$

Así pues, desde los años 90 hasta el estallido de la crisis actual ha ido fraguando en este país una estructura económica parasitaria e improductiva: un entramado de pacotilla, totalmente dependiente del capitalismo de casino a escala mundial y de la supuesta piedra filosofal de la moneda única. Esta maniobra imperialista del eje franco-alemán ha tenido como leitmotiv inundar los mercados cautivos de la periferia europea con sus altamente competitivos productos, financiando a manos llenas, para mantener esta demanda hipertrofiada, las burbujas inmobiliarias y los artificialmente inflados niveles de vida de los ahora llamados inmisericordemente PIGS (Portugal, Irlanda, Grecia y España).

El epítome de la exuberante irracionalidad previa a la catástrofe en curso lo ilustra vivamente el dato de que en 2005 se construyeran más viviendas en España, ique en Francia, Alemania y Gran Bretaña juntas!

Mientras se cebaba esta bomba de relojería, el mafioso contubernio formado por la gran banca (bien dopada con la inyección masiva del ahorro de las potencias del euro), los emperadores del ladrillo y las clientelares administraciones públicas celebraban con gran fanfarria el hallazgo de la fórmula taumatúrgica del crecimiento ilimitado. Negando simultáneamente a coro, con rostro de cemento armado, la existencia de la burbuja y la posibilidad de deflación inmobiliaria.

Todo ello regado a raudales con toneladas de propaganda de falso progreso y confianza en la solidez de los cimientos del "milagro" español (loado entusiásticamente por los oráculos del

gran capital a escala mundial: el Financial Times y el Wall Street Journal), para tapar las alarmantes señales de putrefacción y de colapso inminente que cualquier observador avezado podía meridianamente constatar: una enorme montaña de deuda privada impagable presta a derrumbarse ante las primeras sacudidas sísmicas enviadas por un cataclismo financiero que, dando la razón al viejo Marx, alcanzaría dimensiones sin precedentes.

Este armazón parasitario y carcomido permitió a duras penas a los hijos del baby boom ir trampeando su incorporación a la vida adulta y la autonomía personal: sólo hay que observar la evolución de la natalidad, nupcialidad, edad del primer hijo y demás tasas demográficas para percibir el grado creciente de temor al futuro de los españolitos.

Sin embargo, el soñado ideal pequeñoburgués (basado en la tríada del trabajo fijo, el pisito en propiedad y el núcleo familiar) iba poco a poco volatilizándose a ojos vista ante el aluvión de contratos temporales de baja calidad y los precios prohibitivos de la vivienda. Sombrío panorama que iba metiendo el miedo en el cuerpo a gran parte de la ciudadanía, que constataba con creciente desasosiego la fragilidad de sus asideros laborales y las cada vez más 
lúgubres perspectivas económicas.

Esta es la función de banderín de enganche sociológico de la gran burbuja inmobiliaria y sectores aledaños, al proporcionar un último hálito de engarce vital a toda una generación a costa de sumirla en el pozo de las deudas vitalicias y en el crónico retraso y endeblez de su consolidación socioeconómica, simbolizado en el dato sobrecogedor de que la emancipación de los españoles se produzca a los jtreinta y cuatro años!

Las últimas vigas que sostenían la podrida carcasa, que a duras penas protegían de la exclusión social a las nuevas generaciones (el crédito masivo para sostener el consumo languideciente y el colchón familiar de los sufridos padres del baby boom), iban a amenazar derrumbe inmediato ante cualquier nubarrón económico que asomara por el horizonte.

Es fácil entender que, con esta decrépita estructura, el enésimo crack de alcance mundial, provocado esta vez por el colapso de la mastodóntica estafa piramidal de ingeniería financiera de los trileros de Wall Street, impactaría de lleno en la hipertrofiada y dependiente economía española y destruiría fulminantemente los últimos residuos de falso bienestar que pudieran pretender apuntalar mínimamente la paz social.

Y la historia, en otra vuelta de tuerca, como queriendo descolocar a los apologetas del fin de los conflictos de clase y de la hegemonía triunfal, ya derrotado el enemigo comunista, del neoliberalismo desembridado, empujó de nuevo al mundo a un contexto de incertidumbre, crisis galopante y miseria creciente.

En el preciso momento de volatilizarse este andamiaje de cartón piedra en un nuevo estertor de un capitalismo cada vez más exangüe, millones de españoles e inmigrantes se vieron súbitamente atrapados en el marasmo del paro crónico y las deudas impagables. Mientras tanto, la juventud, sobradamente preparada al haber creído a pies juntillas el mito meritocrático de la cualificación académica como seguro trampolín al mercado de trabajo, veía frustrado fulminantemente su proyecto vital.

Y por fin, en esta dramática coyuntura, el chicle de la apatía y la resignación infinitas (encarnadas en el manoseado cliché del pasotismo juvenil, bien cebado por los anestésicos de todo tipo suministrados por el poder) se rompió ante el flagrante incumplimiento de las promesas del fraudulento contrato social, como refleja lacónicamente uno de los eslóganes del movimiento quincemayista: "juventud sin futuro". 


\section{Agradecimiento:}

No querría concluir sin manifestar mi gratitud a María Bobes González, lectora meticulosa del manuscrito que ha aportado valiosas contribuciones recogidas en la versión definitiva. Obviamente, los múltiples errores u omisiones que todavía persistan son responsabilidad exclusiva del autor de estas líneas.

1 ] Los escritos de Pier Paolo Pasolini y, en concreto, "El artículo de las luciérnagas" (http://lapecerarevista.blogspot.com/2010/06/pier-paolo-pasolini-el-articulo-de-las.html), han sido tributarios caudalosos del presente trabajo por su brillante análisis de las nuevas formas de dominación del régimen capitalista y por su carácter claramente anticipatorio de las lúgubres realidades actuales. Como lúcidamente explica el siguiente comentario, los textos de Pasolini cumplen la doble función de desvelar los sofisticados mecanismos de conformación del consenso en la sociedad crematística y de mantener prendida (venciendo la masiva tendencia al fatalismo cínico frente a esa dominación totalitaria del "poder sin rostro") la llama de la, cada vez más acuciante, necesidad de rebelión:

"Pasolini, efectivamente, anticipó en sus Scritti corsari y Lettere luterane (1976) nuestro presente, no sólo el de Italia. El triunfo de los valores y la economía burguesa y neocapitalista, la homologación total de las culturas subalternas (no de las diferencias de clase, por supuesto) en la civilización burguesa; el triunfo de una lengua y cultura de una nueva civilización tecnocrática, pragmática, totalitaria, basada en la mera comunicación, en la autoridad de los medios de comunicación de masas, y el consecuente genocidio -no sólo de las culturas subalternas- sino de la misma cultura humanista, expresiva y diferenciada. (...)

Son los jóvenes, especialmente, los que deben frecuentar y desentrañar estos textos. Los jóvenes, que no conocieron el mundo de "antes de la desaparición de las luciérnagas", que nacieron bajo la sombra del ya instalado "Poder sin rostro" que aplicaba despiadadamente la política del "Desarrollo" en vez del "Progreso". Estos jóvenes tienen la dura tarea de realizar un doble proceso interior: no sólo imaginar las luciérnagas, sino crearlas nuevamente brillando en los cielos de la sociedad homologada." http://lapecerarevista.blogspot.com/2010/05/pasolinitres-escritos-corsarios.html

2 ] http://toniosantiuste.blogspot.com/2011/06/la-desaparicion-de-las-luciernagas.html

3 ] http://www.rebelion.org/docs/80816.pdf La reaparición de las luciérnagas. Bosquejo histórico por Alfredo Apilánez se encuentra bajo una Licencia Creative Commons Reconocimiento-NoComercial-SinObraDerivada 3.0 Unported 